\section{Spontaneous regression of cutaneous Hodgkin's disease}

Specific lymphomatous infiltration of the skin by Hodgkin's disease is rare and is usually a sign of uncontrolled recurrent disease. Distant cutaneous infiltration may occur preterminally in patients with widespread disease. I now report an exception: disseminated skin lesions regressed spontaneously in a patient who had been treated for stage IA disease. He has remained free of the disease for two and a half years.

\section{Case report}

A 46-year-old milkman presented with a mass in the left axilla. At about the same time he developed total alopecia affecting all body hair. Lymphnode biopsy showed infiltration by Hodgkin's disease of mixed cellularity type. There were no systemic symptoms or other clinical evidence of Hodgkin's disease. Chest radiography, lymphography, and intravenous pyelography showed no abnormalities. Erythrocyte sedimentation rate was $83 \mathrm{~mm}$ in the first hour. No abnormality was found at laparotomy, and the patient was pathologically staged as having stage IA disease. Mantle irradiation was administered, delivering a dose of $40 \mathrm{~Gy}$ (4000 rad) to the midpoint of the chest in 20 fractions over 28 days.

At the completion of radiotherapy a rash was noted. This began on the lower abdomen and left groin and spread to the front of the thighs and the buttocks (see figure). There was an isolated nodule on the left elbow. The

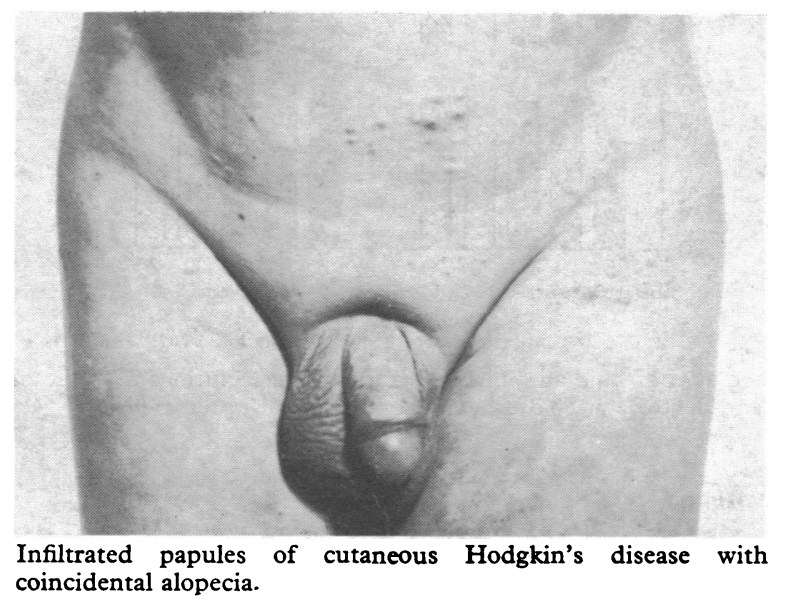

lesions were discrete infiltrated papules, up to $8 \mathrm{~mm}$ in diameter, of a livid red to flesh colour. There was no vesiculation to suggest herpes zoster, and a specific infiltration of the skin by diseased cells was diagnosed clinically. Examination of a biopsy specimen of one of the abdominal lesions showed that the dermis was infiltrated by lymphocytes, plasma cells, eosinophils, mononuclear Hodgkin's cells, and classical binucleate Reed-Sternberg cells. There was no other clinical evidence of Hodgkin's disease; the lymphogram remained normal and the erythrocyte sedimentation rate had fallen to $29 \mathrm{~mm}$ in the first hour. The skin nodules resolved spontaneously within one month. At about the same time the patient's hair started to regrow. Alopecia areata was diagnosed retrospectively and thought to be coincidental. There has been no further evidence of recurrent Hodgkin's disease two and a half years after treatment.

\section{Comment}

Non-specific cutaneous lesions occur in $13-53 \%$ of cases of Hodgkin's disease. The skin is not histologically affected, and the commonest lesions are prurigo-like papules, herpes zoster, increased pigmentation, and exfoliative dermatitis. ${ }^{1}$

Specific lymphomatous infiltration of the skin is rarer and usually occurs as an extension of uncontrolled infiltration of adjacent lymph nodes. ${ }^{1}$ The skin may also become infiltrated distal to massive nodal disease, and in such cases retrograde lymphatic spread has been suggested. ${ }^{2}$ Surgical implantation of lymphomatous tissue in the skin may occur, especially after repeated biopsy or attempted block dissection.

Cutaneous Hodgkin's disease as the sole evidence of recurrence has been reported by Rubins. ${ }^{3}$ His patient developed widespread skin lesions unrelated to initial nodal disease, which was in remission after radiotherapy. Sequential single-agent chemotherapy administered over four years controlled the disease but did not eradicate it. Primary cutaneous Hodgkin's disease is rare and may have a good prognosis. Only 17 cases have been reported." This type of Hodgkin's disease may suggest an unusual relation between tumour and host. It probably arises by the haematogenous route, the lymphoma being localised by organ-specific factors. Szur et $a l^{5}$ observed three such patients for several years: there was no evidence to suggest that other organs were affected, and two patients showed spontaneous partial regression and remained untreated.

Biopsy is essential in the diagnosis of cutaneous Hodgkin's disease. After staging the disease, treatment should be dictated by the extent to which other organs are affected. If only the skin is affected a period of observation is indicated unless the lesions are symptomatic.

I thank Dr C L Harmer, consultant radiotherapist and oncologist, for permission to report this case and Dr J P Sloane for reviewing the histological material.

1 Smithers DW. Hodgkin's disease. London: Churchill-Livingstone, 1973.

2 Benninghoff DL, Medina A, Alexander LL, Camiel MR. The mode of spread of Hodgkin's disease to the skin. Cancer 1970;26:1135-40.

3 Rubins J. Cutaneous Hodgkin's disease. Cancer 1978;42:1219-21.

4 Wood NL, Coltman CA. Localised primary extranodal Hodgkin's disease. Ann Intern Med 1973;78:113-8.

5 Szur L, Harrison CV, Levene GM, Samman PD. Piimary cutaneous Hodgkin's disease. Lancet 1970;i:1016-20.

(Accepted 11 Fanuary 1980)

Department of Radiotherapy and Oncology, Royal Marsden Hospital, Sutton, Surrey SM2 5PT

M V WILLIAMS, MRCP, registrar (now at the Gray Laboratory, Mount Vernon Hospital, Northwood, Middlesex HA6 2RN)

\section{Rhesus immunisation during pregnancy: the case for antenatal anti-D}

In a previous report ${ }^{1}$ we surveyed the deaths from rhesus haemolytic disease of the newborn during 1977 in England and Wales. This was done, firstly, to assess the accuracy of death certification by doctors and of coding by the Office of Population Censuses and Surveys and, secondly, to look at problems associated with the present (postnatal) anti-D prophylaxis programme. Here there is difficulty when women have been immunised during pregnancy, for in these cases anti-D given postnatally is too late.

We describe here an example of the problem, and using strict criteria we now think that 12 (not 16) of the 110 women in our 1979 paper $^{1}$ were probably immunised during, and not after, the immunising pregnancy. Moreover, in most of them antibodies were found only after the 28th week and therefore antenatal anti-D should have helped. There is good evidence from other countries that antenatal anti-D given at about the 28th and 34th weeks, in addition to the routine postnatal dose, can substantially reduce the small failure rate of the standard postnatal programme. ${ }^{2}$

The easiest patients to assess are those in whom antibodies are found during the first pregnancy, the baby being rhesus positive and the mother never having had a transfusion of rhesus-positive blood. There is then strong evidence that the primary immunisation did occur before term. On the other hand, if antibodies are first found during a second or subsequent pregnancy, there is always the possibility that they may have been formed in response to an earlier stimulus, the antibodies not necessarily being serologically detectable at this time ("sensibilisation").

\section{Case report}

In this case (case 501) the infant, who died from rhesus haemolytic disease, was born live in March 1977. Her mother was blood group A cde/cde and father blood group AB homozygous D. In August 1972 the mother had suffered an "inevitable abortion" and had been given anti-D. She conceived again in August 1973, was booked for admission in March 1974, and was admitted for induction in May 1974. A baby girl was born whose blood group 
was $\mathrm{B}$-that is, $\mathrm{ABO}$ incompatible-cDe/cde. The baby's bilirubin concentration rose to $178 \mu \mathrm{mol} / 1(10.4 \mathrm{mg} / 100 \mathrm{ml})$; she was jaundiced and had a positive Coombs test result but was not badly affected.

Antibody studies in the 9th and 29th weeks of the second pregnancy showed no antibodies on either occasion, anti-D being first detected at delivery.

In March 1977 another girl was born (the index case), but she died in the first week after undergoing two intrauterine transfusions and one exchange transfusion. Her haemoglobin concentration was $4.5 \mathrm{~g} / \mathrm{dl}$ and necropsy confirmed erythroblastosis.

\section{Comment}

We originally scored this case as a failure of anti-D prophylaxis but now think that the mother was probably immunised during the second pregnancy.

Data on the scoring of the other 15 cases are available on request, as are reprints of our 1979 paper. $^{1}$

Because of the substantial number of women who are immunised during pregnancy we believe that there is a strong case for introducing an antenatal anti-D programme in Britain. Since there are deficiencies in implementing the present postnatal regimen, however, we think that these should be remedied before the more complex antenatal programme is started.

Our thanks are due to Professor P L Mollison FRS, who suggested this investigation and gave us the benefit of his advice in assessing the cases.

Correspondence should be addressed to: Sir Cyril Clarke, Medical Services Study Group of the Royal College of Physicians, 126 Albert Street, London NW1 $7 \mathrm{NF}$

1 Clarke Sir Cyril, Whitfield AGW. Deaths from rhesus haemolytic disease in England and Wales in 1977: accuracy of records and assessment of anti-D prophylaxis. Br Med f 1979; :1665-9.

${ }^{2}$ Davey MG, Zipursky A. Report on McMaster conference on prevention of Rh immunisation. Vox Sang $1979 ; 36: 50-64$

(Accepted 17 December 1979)

Medical Services Study Group of the Royal College of Physicians, London NW1 7NF

SIR CYRIL CLARKE, FRS, MD, FRCP, director

A G W WHITFIELD, MD, FRCP, assistant directo

\section{Fluid deprivation due to Althesin solution affecting drop size}

Fluid balance is an increasingly important facet of patient management in intensive therapy units (ITUs). Calculations of input based on drip rate alone are notoriously inaccurate, with estimated errors of up to $20 \% .^{12}$ Attempts have been made to overcome these errors by using a drip set in conjunction with a peristaltic infusion pump, and this method has been used in our ITU with an acceptable degree of accuracy. In a recent case, however, while $10 \%$ Althesin (alphaxalone and alphadalone in saline with polyoxyethylated castor oil) in 5\% dextrose was being given to a child via a paediatric infusion set fluid balance measurements showed a deficit of about $50 \%$ between calculated and administered volumes. We therefore investigated the performance of adult and paediatric infusion sets and the performance and viscosity of Althesin.

\section{Methods and results}

All intravenous administration sets used in the United Kingdom must meet British Standard 2463:1962. Statements made on the packaging indicate that the adult sets-for example, Travenol FKG2055-give $1 \mathrm{ml}$ per 15 drops. Our measurements revealed, however, that while this was true for blood, the accurate figure for saline, water, etc, was $1 \mathrm{ml}$ per 20 drops. Subsequent communication with the manufacturers has confirmed these figures. Paediatric sets-for example, Soluset, Metriset-are accepted as being more accurate and deliver $1 \mathrm{ml}$ per 60 drops.

Althesin is a steroid intravenous anaesthetic agent used in an infusion to provide total intravenous anaesthesia by virtue of its short action and minute-to-minute control of the depth of narcosis. ${ }^{3}$ It is also used in neurosurgery to reduce the cerebral oxygen consumption, cerebral blood flow, and, therefore, intracranial pressure. ${ }^{4}$ We have used it in our ITU for severe head injuries. In addition, the solution provides the main daily fluid input.

Five per cent dextrose was the control and diluent of choice in preparing $10 \%$ and $20 \%$ Althesin solutions; $100-\mathrm{ml}$ aliquots were measured with the paediatric burette supplied with the set. Each set was controlled to deliver a drip rate of 60 drops per minute by the use of a single Tekmar T51 pump and T22 drip detector. The volume delivered over a series of 15-minute periods was measured by volume depletion in the burette and compared with the calculated volume. From this the deficit was derived. We repeated this test with $20 \%$ and $50 \%$ dextrose solutions. We also used the same procedure with adult giving sets, except that the volume delivered in the 15-minute period was measured using a standard measuring cylinder. The viscosity of all the solutions was measured with the Oswald Viscometer. The results indicated that the effect of viscosity on drop size was minimal. For example, although $50 \%$ dextrose was $234.6 \%$ more viscous than water, the given volume was only $3 \cdot 2 \%$ less than that predicted. The figure represents the amount of fluid delivered at 60 drops per minute. In the case of $20 \%$ Althesin the administered fluid volume $(35.5 \mathrm{ml})$ was almost half of that predicted.

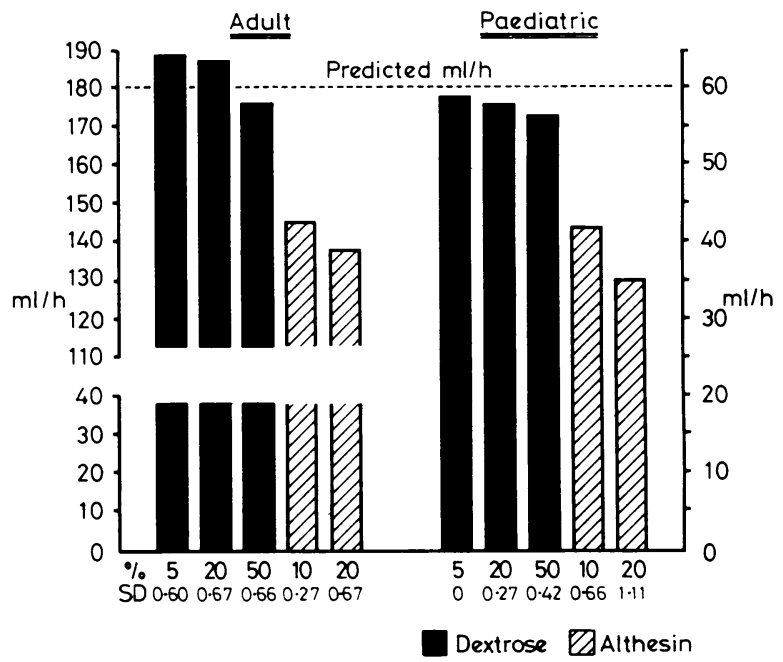

Amount of fluid administered from various solutions of Althesin and dextrose at $60 \mathrm{drops} / \mathrm{min}$ compared with predicted.

\section{Comment}

The formula for determining drip rate is:

$$
\mathrm{V}=\frac{\pi \mathrm{d} \gamma}{\mathrm{p} g}
$$

Where $\mathrm{V}=$ volume of drop, $-\mathrm{d}=$ effective circumference, $\gamma=$ surface tension, $f=$ specific gravity, and $g=$ gravitational force. Althesin is dissolved in a surfactant polyoxyethylated castor oil. ${ }^{5}$ This lowers the surface tension of the solution and, therefore, as can be seen from the formula, the drop size will be reduced.

The surfactant properties of drugs administered by continuous infusion should therefore be known so that similar volumetric errors may be avoided. Solutions of Althesin and other drugs which may have an effect on surface tension should ideally be administered by a volumetric infusion pump.

1 Farenchak P, Collins J, Morgan A. Drop size and rate in parenteral infusion. Surgery 1971 ;70:674-9.

2 Flack FC, Whyte TD. Behaviour of gravity-fed administration sets used for intravenous infusion. $B r$ Med $\mathcal{F} 1974$;iii :439-43.

3 Savage TM, Ramsay MAE, Curran JPJ, Cotler J, Walling PT, Simpson $\mathrm{BP}$. Intravenous anaesthesia by infusion. A technique using alphaxalone/ alphadalone (Althesin). Anaesthesia 1975;30:757-64.

${ }^{4}$ Sari A, Mackawa, Tokio M, Okuda I, Takeshita H. Effects of Althesin on cerebral blood flow and oxygen consumption in man. $\mathrm{Br} \mathcal{F}$ Anaesth $1976 ; 48: 545-50$

${ }^{5}$ Data Sheet Compendium 1979;330.

(Accepted 18 December 1979)

Department of Anaesthesia, Royal Free Hospital, London NW3 W J WRAIGHT, DOBSRCOG, FFARCS, senior anaesthetic registrar D J COX, medical physics technician 